\title{
Retinoic Acid Decorated Albumin-Chitosan Nanoparticles for Targeted Delivery of Doxorubicin Hydrochloride in Hepatocellular Carcinoma
}

\author{
Jaleh Varshosaz, ${ }^{1}$ Farshid Hassanzadeh, ${ }^{2}$ Hojjat Sadeghi, ${ }^{3}$ \\ Zahra Ghelich Khan, ${ }^{1}$ and Mahboobeh Rostami ${ }^{2}$ \\ ${ }^{1}$ Department of Pharmaceutics, School of Pharmacy and Novel Drug Delivery Systems Research Centre, \\ Isfahan University of Medical Sciences, P.O. Box 81745-359, Isfahan, Iran \\ ${ }^{2}$ Department of Medicinal Chemistry, School of Pharmacy, Isfahan University of Medical Sciences, Isfahan, Iran \\ ${ }^{3}$ Department of Biotechnology, School of Pharmacy, Isfahan University of Medical Sciences, Isfahan, Iran
}

Correspondence should be addressed to Jaleh Varshosaz; varshosaz@pharm.mui.ac.ir

Received 9 February 2013; Accepted 1 April 2013

Academic Editor: Mohamed Bououdina

Copyright (c) 2013 Jaleh Varshosaz et al. This is an open access article distributed under the Creative Commons Attribution License, which permits unrestricted use, distribution, and reproduction in any medium, provided the original work is properly cited.

\begin{abstract}
Retinoic acid (R) grafted chitosan (C) copolymers with different degree of substitution of retinoic acid on the chitosan were synthesized. Retinoic acid targeted chitosan-albumin nanoparticles were prepared for targeted delivery of doxorubicin in hepatocellular carcinoma by coacervation method. Physical properties of nanoparticles including particle size, zeta potential, drug loading efficiency, and drug release profiles were studied. TEM micrographs were taken to see the morphology of nanoparticles. The cytotoxicity of doxorubicin-loaded nanoparticles was studied on HepG2 cells using MTT assay and their cellular uptake by fluorescence microscopy. FTIR and ${ }^{1}$ HNMR spectra confirmed successful production of RC conjugate which was used in production of the targeted $\mathrm{RC}$-albumin nanoparticles. $\mathrm{IC}_{50}$ of drug loaded in these nanoparticles reduced to half and one-third compared to nontargeted nanoparticles and free drug, respectively.
\end{abstract}

\section{Introduction}

Hepatocellular carcinoma (HCC) is the fifth most common malignancy in the world, the most common primary malignancy of the liver, and the third most common cause of cancer deaths $[1,2]$. The data from epidemiological surveys show that the incidence is rising in North America, Oceania, and central Europe [1]. Unfortunately, the 5-year survival rate of the disease is very low $(<5 \%)$, and about 600,000 lives are lost each year because of HCC [3]. Important risk factors for HCC include hepatitis B and chronic hepatitis C infection, alcoholic cirrhosis, and nonalcoholic steatohepatitis [4].

Patients diagnosed at early stage benefit from surgical resection, percutaneous ablation, and liver transplant, but more than $80 \%$ of patients are diagnosed at intermediate stage [5-9]. Even after curative treatments like resection or percutaneous ablation the recurrence rate is high [10]. The other problem is poor sensitivity to radiotherapy and high resistance to available anticancer drugs [11, 12]. In addition, side effects of chemotherapeutic agents are one of major limitations in cancer treatment; for example, cardio toxicity is one of most important risks of anthracyclines which are used in different types of malignancies including: leukemias, lymphomas, breast, uterine, ovarian, and lung cancers. Suggested mechanisms of action for anthracyclines are three mechanisms: (1) inhibition of DNA and RNA synthesis by intercalating between base pairs of the DNA/RNA strand, thus preventing the replication of rapidly growing cancer cells, (2) inhibition of topoisomerase II enzyme, preventing the relaxing of supercoiled DNA and thus blocking DNA transcription and replication, and (3) creation of ironmediated free oxygen radicals that damage the DNA and cell membranes [13, 14]. The most important reported side effects of these drugs include cardiotoxicity and vomiting which considerably limit their usefulness. Considering these facts, 
designing a drug delivery system with minimum possible side effects appears to be reasonable.

Nanoparticulate drug carriers require more considerations in HCC, because Kupffer cells in liver sinusoids take up the nanoparticles and make the drug delivery difficult [1517]. If the nanoparticle is targeted somehow to release the drug almost only into HCC affected liver cells, the cytotoxic activity will be less than nontargeted ones as was shown with doxorubicin [18]. Vascular endothelial growth factor, growth factor receptor, galactose, transferrin, folate, and retinoic acid can be used as potential targeting agents in HCC [19-23]. Among them retinoic acid would be one of the best choices since the retinoic acid receptor- $\alpha$ is reported as the dominant receptor in HCC, and its mRNA has been shown to be at low levels in normal liver but at high levels in $\operatorname{HCC}[22,24]$.

Retinoic acid ( $R$ ) is a derivative of vitamin A with an important role in regulation of cell proliferation and differentiation [25], and its inhibitory effect on cancer cell growth is well established [26-30].

Chitosan (C) a chitin derivative is the second biomass found in huge amounts on earth and along with its derivatives is known as a low-toxic, biocompatible, biodegradable, mucoadhessive, and low production cost material [31, 32] which has been used as a delivery system for proteins, nutraceuticals, gene, and drugs [33-37]. Because of its positively charged nature at low $\mathrm{pH}$ values, chitosan can associate with anions to form polyelectrolytes in solution [31].

Albumin, a versatile protein carrier for drug delivery, has been shown to be nontoxic, nonimmunogenic, biocompatible and biodegradable. Therefore, it is ideal material to fabricate nanoparticles for drug delivery. Albumin nanoparticles have gained considerable attention owing to their high binding capacity of various drugs and being well tolerated without any serious sideeffects [38].

Ionic coacervation method is a suitable preferred technique for production of nanoparticles as colloidal drug carriers which have the capability of being decorated with the specific receptor binding ligands. Since there is no organic solvent used in this method and nanoparticles are prepared without involving toxic cross linking agents like glutaraldehyde, the resulting nano-dispersion has no toxic residue to be removed which, in turn reduces production costs, and a safer drug delivery system will be resulted.

The aim of the present study was designing a targeted delivery system of doxorubicin to hepatocellular carcinoma by anchoring retinoic acid to chitosan-albumin nanoparticles. Epirubicin is the anticancer agent of choice used in HCC [23], but as there is no evidence suggesting any survival or response difference between epirubicin and its isomer, doxorubicin, at similar doses [39], doxorubicin was used in the present study due to its lower cost.

\section{Materials and Methods}

2.1. Materials. Doxorubicin $\mathrm{HCl}$ was provided from Hangzhou ICH Biopharm Co., Ltd. (Zhejiang, China), retinoic acid from Solmag (Italy), and chitosan oligosaccharide $(90 \%$ deacetylated, $\mathrm{Mw}=8.6 \mathrm{kDa})$ was supplied by Yuhuan Marine Biochemistry Co., Ltd. (Zhejiang, China).
N-hydroxysuccinimide (NHS), N, N'-Dicyclohexylcarbodiimide (DCC), and 3-[4, 5-dimethylthiazol-2-yl]-2, 5diphenyl tetrazolium bromide (MTT) were from Sigma (USA). Egg albumin, anhydrous dimethylsulfoxide (DMSO), and acetic acid were from Merck Chemical Company (Germany). RPMI-1640 culture medium was from PAA (Austria) and antibiotic mixtures were from GIBCO Laboratories (Scotland). HepG2 cell line was supplied by Pasteur Institute (Iran).

2.2. Preparation of Retinoic Acid Anchored Chitosan (RC). The coupling reaction of retinoic acid and chitosan was done as reported in our previous work [40] with little change. Briefly, chitosan (2 g) was dissolved in acetate buffer $(0.1 \mathrm{M}$, $\mathrm{pH}$ 4.7). Retinoic acid (calculated amounts for substituting 2 and 4 amine groups), DCC, and NHS (each in 1.5-fold of R) were dissolved in $12 \mathrm{~mL}$ of anhydrous DMSO, and after $24 \mathrm{hr}$ of stirring under nitrogen flush, this solution was added drop wise to chitosan solution and was left to be stirred overnight in darkness at room temperature. After completion of the reaction, diluted aqueous solution of $\mathrm{NaOH}$ was added drop wise to adjust the $\mathrm{pH}$ of reaction flask to 9 . The product was then dialyzed (Mw cutoff 2000, Membra-Cel, Viskase, USA) against phosphate buffer at $\mathrm{pH} 7.4$ and water (each for 2 days) and finally lyophilized for maximum purification (Freezedryer, Christ, $\alpha-2-4$ LDPlus, Germany). Chitosan with 2 or 4 groups substituted was tagged as R2 or R4, respectively.

2.3. Preparation of RC-Albumin Nanoparticles. To fabricate RC-albumin nanoparticles, an aqueous coacervation technique was used. Different amounts of each type of synthesized RC (6.66-66.6 mg of R4 or R2) were dissolved by levigating with a few drops of water and acetic acid. Then enough water was added, and the $\mathrm{pH}$ was adjusted to 2.49. The solution was then sonicated using probe sonicator (HD 3200, Bandeline, Germany) for $4 \mathrm{~min}$ with the power of $40 \mathrm{w}$ for amounts less than $50 \mathrm{mg}$ and $60 \mathrm{w}$ for $50 \mathrm{mg}$ and more. The drug (2.6$50 \mathrm{mg}$ ) was then added to this solution while being stirred. The albumin solution was prepared simply by dissolving egg albumin (3.34-50 mg) in deionized water. In the next step, albumin solution was added drop wise to the solution of RC while being stirred at $600 \mathrm{rpm}$.

2.3.1. Experimental Design. To evaluate the effect of processing variables on the responses of particle size, zeta potential, encapsulation efficiency (EE\%), and drug release efficiency $(\mathrm{RE} \%)$ and to screen the most effective ones, an irregular factorial design was used. Four different variables including total polymer, polymer type, albumin amount, and drug content were studied each in two levels. Table 1 shows the four control factors selected in the optimization study.

An overview of the formulations investigated is presented in Table 2.

A run involved the corresponding combination of levels to which the factors in the experiment were set. All experiments were done in triplicate. The effects of the studied variables on the responses were then analyzed by the Design Expert software (Version 7.1, USA) to obtain 
TABLE 1: Description and trial levels of studied factors in irregular factorial design used in preparation of doxorubicin loaded in RCalbumin nanoparticles.

\begin{tabular}{lcc}
\hline Studied variables & & Levels \\
& I & II \\
\hline Total mass of RC-albumin (mg) & 10 & 100 \\
Polymer type & R2 & R4 \\
Albumin/RC & 0.5 & 1 \\
Drug/RC-albumin & 0.25 & 0.5 \\
\hline
\end{tabular}

TABLE 2: Composition of different formulations investigated in preparation of doxorubicin loaded in RC-albumin nanoparticles using irregular factorial design.

\begin{tabular}{lcccc}
\hline $\begin{array}{l}\text { Formulation } \\
\text { code }\end{array}$ & $\begin{array}{c}\text { Total mass of } \\
\text { RC-albumin } \\
(\mathrm{mg})(\mathrm{A})\end{array}$ & $\begin{array}{c}\text { Albumin/RC } \\
(\mathrm{B})\end{array}$ & $\begin{array}{c}\text { Drug/RC- } \\
\text { albumin } \\
(\mathrm{C})\end{array}$ & $\begin{array}{c}\text { Polymer } \\
\text { type } \\
(\mathrm{D})\end{array}$ \\
\hline $\mathrm{A}_{100} \mathrm{~B}_{1} \mathrm{C}_{0.5} \mathrm{R} 2$ & 100 & 1 & 0.5 & $\mathrm{R} 2$ \\
$\mathrm{~A}_{10} \mathrm{~B}_{0.5} \mathrm{C}_{0.5} \mathrm{R} 2$ & 10 & 0.5 & 0.5 & $\mathrm{R} 2$ \\
$\mathrm{~A}_{10} \mathrm{~B}_{0.5} \mathrm{C}_{0.25} \mathrm{R} 2$ & 10 & 0.5 & 0.25 & $\mathrm{R} 2$ \\
$\mathrm{~A}_{100} \mathrm{~B}_{0.5} \mathrm{C}_{0.5} \mathrm{R} 4$ & 100 & 0.5 & 0.5 & $\mathrm{R} 4$ \\
$\mathrm{~A}_{100} \mathrm{~B}_{0.5} \mathrm{C}_{0.5} \mathrm{R} 2$ & 100 & 0.5 & 0.5 & $\mathrm{R} 2$ \\
$\mathrm{~A}_{10} \mathrm{~B}_{1} \mathrm{C}_{0.5} \mathrm{R} 2$ & 10 & 1 & 0.5 & $\mathrm{R} 2$ \\
$\mathrm{~A}_{100} \mathrm{~B}_{1} \mathrm{C}_{0.25} \mathrm{R} 2$ & 100 & 1 & 0.25 & $\mathrm{R} 2$ \\
$\mathrm{~A}_{100} \mathrm{~B}_{0.5} \mathrm{C}_{0.25} \mathrm{R} 4$ & 100 & 0.5 & 0.25 & $\mathrm{R} 4$ \\
$\mathrm{~A}_{10} \mathrm{~B}_{1} \mathrm{C}_{0.5} \mathrm{R} 4$ & 10 & 1 & 0.5 & $\mathrm{R} 4$ \\
$\mathrm{~A}_{100} \mathrm{~B}_{1} \mathrm{C}_{0.25} \mathrm{R} 4$ & 100 & 1 & 0.25 & $\mathrm{R} 4$ \\
$\mathrm{~A}_{10} \mathrm{~B}_{0.5} \mathrm{C}_{0.25} \mathrm{R} 4$ & 10 & 0.5 & 0.25 & $\mathrm{R} 4$ \\
$\mathrm{~A}_{10} \mathrm{~B}_{1} \mathrm{C}_{0.25} \mathrm{R} 4$ & 10 & 1 & 0.25 & $\mathrm{R} 4$ \\
\hline
\end{tabular}

independently the main effects of these factors, followed by the analysis of variance (ANOVA) to determine which factors were statistically significant. The optimum conditions were determined by the optimization method to yield a heightened performance.

2.4. Particle Size and Zeta Potential Measurements. The mean particle size and zeta potential of RC-albumin nanoparticles were measured by photon correlation spectroscopy (PCS) at a fixed angle of $90^{\circ}$ (Zetasizer, ZEN 3600, Malvern Instrumental, UK). Nanodispersion was suitably diluted to measure mean particle size and polydispersity index.

2.5. Entrapment Efficiency. A $600 \mu \mathrm{L}$ of RC-albumin nanodispersion was centrifuged (Microcentrifuge Sigma $30 \mathrm{k}$, UK) at $10000 \mathrm{rpm}$ for $5 \mathrm{~min}$ in eppendorf tubes (cut-off $10000 \mathrm{Da}$ ). The supernatant, containing the free drug, was diluted 1:7 with deionized water, and the UV absorbance of resulting solution was evaluated spectrophotometrically (UV-mini 1240, Shimadzu, Kyoto, Japan) at $\lambda_{\max }=247 \mathrm{~nm}$. The solution contained all components but the drug was used as the blank. The amount of entrapped drug was determined through the difference between the total and the free drug. The entrapment efficiency (EE) of doxorubicin in RCalbumin nanoparticles was calculated using the following:

$$
\mathrm{EE}(\%)=\frac{\text { entrapped drug in nanoparticles }}{\text { total amoutn of drug added }} \times 100 .
$$

2.6. Drug Release Studies. Two $\mathrm{ml}$ of each nanoparticle dispersion was transferred to a dialysis bag (Mw cutoff 12000 , Membra-Cel, Viskase, USA), and the bag was placed in phosphate buffer solution ( $\mathrm{pH} 7.4$ ) containing $2 \%$ Tween 20 while stirred at $37 \pm 1^{\circ} \mathrm{C}$. $700 \mu \mathrm{L}$ samples were taken and doxorubicin absorbance of each sample was measured at $\lambda_{\max }=499.4 \mathrm{~nm}$ at specific time intervals until $70 \%$ of entrapped drug was released into the media. The parameter of release efficiency within $60 \mathrm{~min}\left(\mathrm{RE}_{60} \%\right)$ was used to compare the release profiles:

$$
\mathrm{RE}_{60} \%=\frac{\int_{0}^{t} y \cdot d t}{y 100 \cdot t} \times 100 .
$$

2.7. Optimization of the RC-Albumin Nanoparticle Formulations. Data processing was done using Design Expert soft ware and the effects of each independent variable on the studied responses were, determined. All responses fitted in the linear model.

The constraints of particle size was $148.0 \leq Y_{1} \leq$ $472.2 \mathrm{~nm}$ with particle size targeted on minimum, for zeta potential it was $29.3 \leq Y_{2} \leq 46.8 \mathrm{mV}$ while it was desired to be in range of obtained results, for loading efficiency the constraints were $7.3 \leq Y_{3} \leq 58.0 \%$ with the goal set at the maximum and $\mathrm{RE}_{60} \%$ had constraints of $41.5 \leq Y_{4} \leq 76.8 \%$ with desired target set at the maximum.

2.8. Transmission Electron Microscopy (TEM). Samples of well-dispersed optimum formulation of nanoparticles were placed on a 300 mesh carbon coated copper grid, and the grid was left to dry in room temperature.Micrographs were taken with different levels of magnification with an accelerating voltage of $80 \mathrm{kv}$ using a transmission electron microscope (Zeiss, EM10C, Germany).

2.9. Cell Culture. HepG2 cells (purchased from the Pasture Institute, Iran) were maintained in tissue culture flask in $5 \% \mathrm{CO}_{2}, 95 \%$ humidified atmosphere at $37^{\circ}$ in RPMI-1640 medium containing 10\% (v/v) of FBS (Fetal Bovine Serum), and $1 \%$ of antibiotics mixture (penicillin/streptomycin $50 \mathrm{IU} / \mathrm{mL}$ ).

2.10. Cell Proliferation Assay (MTT Assay). HepG2 cells in logarithmic phase of growth were plated in 96-well plates at $2 \times 10^{4} \mathrm{cells} / \mathrm{mL}$ and grown for $24 \mathrm{hr}$. The cells were then treated with doxorubicin-loaded RC-albumin nanoparticles, chitosan-albumin nontargeted nanoparticles, and free doxorubicin all at $0.25,0.5$, and $1 \mu \mathrm{g} / \mathrm{mL}$ concentrations at $37^{\circ} \mathrm{C}$ for $48 \mathrm{hr}$. In each case blank nanoparticles with the same concentration were used for comparison. After this period, each well was exposed to $20 \mu \mathrm{L}$ of MTT, and plates were 
incubated for an additional $3 \mathrm{hr}$. Then in each well, the culture medium was removed and blue-violet formazan crystals were dissolved by adding $150 \mu \mathrm{L}$ of DMSO. The absorbance of each well was measured at wavelength of $570 \mathrm{~nm}$ using an ELISA plate reader (Awareness, USA). Untreated cells and cells treated with doxorubicin were used as negative and positive controls, respectively.

2.11. Cellular Uptake Studies. The cellular uptake tests on HepG2 cells were performed after $24 \mathrm{hr}$ culturing the cells. The nanoparticles were loaded with sodium fluorescein as the fluorescent probe marker. The remained free marker was removed by dialyzing against deionized water, and then the washed loaded nanoparticles were used for the cellular uptake test. Then sodium fluorescein-labeled nanoparticles of RC-albumin nanoparticles, nontargeted chitosan-albumin nanoparticles, and also the solution of sodium fluorescein were incubated with the cells for 1 and $4 \mathrm{hr}$, and then micrographs were taken using visible or fluorescent light using a fluorescent microscope (Olympus, IX71, Japan).

\section{Results and Discussion}

3.1. Synthesis of RC Copolymer. The synthesis of RC copolymer was confirmed by ${ }^{1} \mathrm{H}$ NMR and FT-IR spectra. The results are shown in Figures 1 and 2.

${ }^{1} \mathrm{H}$ NMR spectra $\left(400 \mathrm{MHz}, \mathrm{DMSO}-\mathrm{d}_{6}\right)$ of $\mathrm{R}, \mathrm{C}$, and $\mathrm{RC}$ copolymer are shown in Figure 1. Absence of the acidic proton of $\mathrm{R}$ in the area of $12 \mathrm{ppm}$ with the downfield shift of the ( $\mathrm{g}$ ) proton of retinoic acid accompanying with the presence of other reference picks of chitosan and $\mathrm{R}$ led us to conclude that the chemical bonding between chitosan and $\mathrm{R}$ has occurred.

FT-IR spectra of these substances are shown in Figure 2. The absorption band at $1635 \mathrm{~cm}^{-1}$ in spectra of chitosan (Figure 2(a)) was attributed to the carbonyl of $\mathrm{O}=\mathrm{C}-\mathrm{NHR}$ of chitosan, and the absorption band at $1521 \mathrm{~cm}^{-1}$ was assigned to the amino groups of chitosan with high deacetylation degrees. The absorption band at $1680 \mathrm{~cm}^{-1}$ in spectra of $\mathrm{R}$ (Figure 2(b)) was assigned to the carbonyl group of $\mathrm{R}$, and the absorption band around $2931 \mathrm{~cm}^{-1}$ was attributed to its aliphatic alkanes. In the spectra of RC (Figure 2(c)) additional absorption band that has appeared at $1736 \mathrm{~cm}^{-1}$ demonstrated conjugation between $\mathrm{R}$ and chitosan; furthermore, the presence of other reference bands of $\mathrm{R}$ and chitosan indicates the occurrence of conjugation between $\mathrm{R}$ and chitosan.

3.2. Particle Size. Twelve different formulations of RCalbumin nanoparticles loaded with doxorubicin (Table 1) were prepared, and their physical properties were measured as shown in Table 3.

As it can be seen in Figure 3, mean diameter of nanoparticles is dependent mainly on the interaction between polymer type and drug content. Statistical analysis of the results showed that increase in degree of substitution of $\mathrm{R}$ in copolymer led to decrease in particle size. The total mass of copolymer and albumin also had a significant impact on particle diameter. Comparing the contribution percentage of total mass of copolymer and albumin with the ratio of albumin/RC on the particle size of nanoparticles (Figure 3), it can be concluded that the albumin part of the total amount of RC-albumin plays a quite less significant role than the chitosan part.

Retinoic acid is a hydrophobic molecule, so the more retinoic acid is attached to chitosan the less water soluble it will be, and this causes enhancement in hydrophobic interactions which make the particle decrease its surface, and more packed nanoparticles will be formed [40].

On the other hand, doxorubicin is protonated in nano dispersion and is a water soluble drug [41], so the drug entrapped in particles naturally tends to leave them and enter the water. When hydrophobic interactions were less significant (R2 compared to R4) the particles could swell. The total mass of copolymer and albumin also had a significant impact on particle diameter. From previous studies [42-44] it was expected that increased chitosan concentration led to increase in size.

Comparing the contribution percentage of total mass of copolymer-albumin with the ratio of albumin/RC on the particle size of nanoparticles (Figure 3), it can be concluded that the albumin part of the total amount of copolymer and albumin plays a quite less significant role than the chitosan part. Even statistical analysis of the effect of each variable on the particle size showed that albumin/RC caused decrease in the particle size of nanoparticles. The increase in albumin concentration induced more negative charge in nanodispersion, and the positively charged chitosan molecules formed more ionic bonds which made the particles wall to form tighter surface leading to the shrinkage and decrease in the surface of the particles, so in higher amounts of albumin, the effect of chitosan in increasing the size is somewhat attenuated.

3.3. Zeta Potential. As Figure 4 indicates the zeta potential of nanoparticles depended mostly on the amount of total mass of RC-albumin and the interaction between the drug content and albumin. Statistical analysis showed that in drug content level of 0.25 increasing the albumin to RC ratio had a slim effect on zeta potential but, as the albumin concentration was increased, switching to higher level of drug content had quite significant impact on zeta potential.

Zeta potential is often a key factor in the stability of colloidal dispersions. Table 3 indicates that the changes of zeta potential were between $39.5 \pm 1.8$ to $46.8 \pm 3.2 \mathrm{mV}$. This demonstrates that the nanoparticles dispersion obtained by coacervation method in an aqueous system is a physically stable system. As Figure 4 indicates the zeta potential of nanoparticles depended mostly on the amount of total mass of RC-albumin and the interaction between the drug content and albumin. As was mentioned before, albumin imparts negative charge to the nanoparticles, and the higher albumin concentration resulted in less positively charged nanoparticles. This reducing impact on zeta potential is more profound than the increasing effect of chitosan on zeta potential (Figure 4).

Freitas and Müller [45] have shown that the increased drug content could reduce the charge density and absolute 


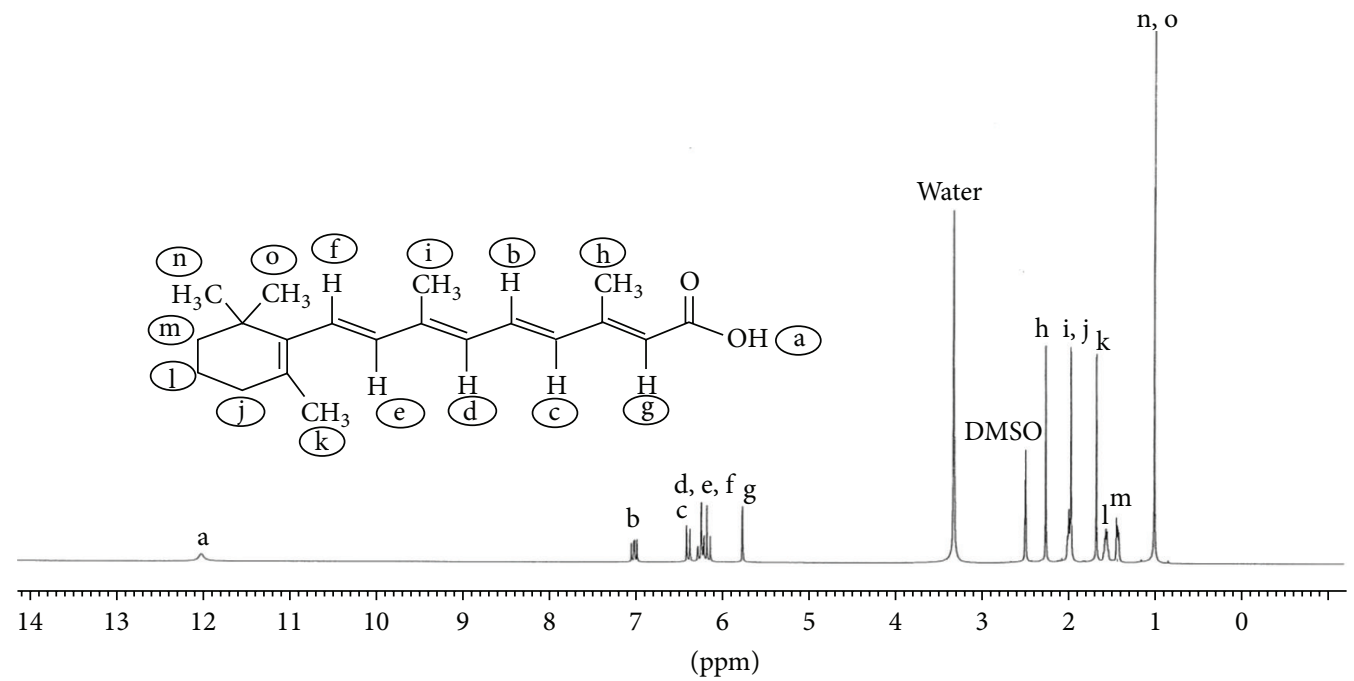

(a)

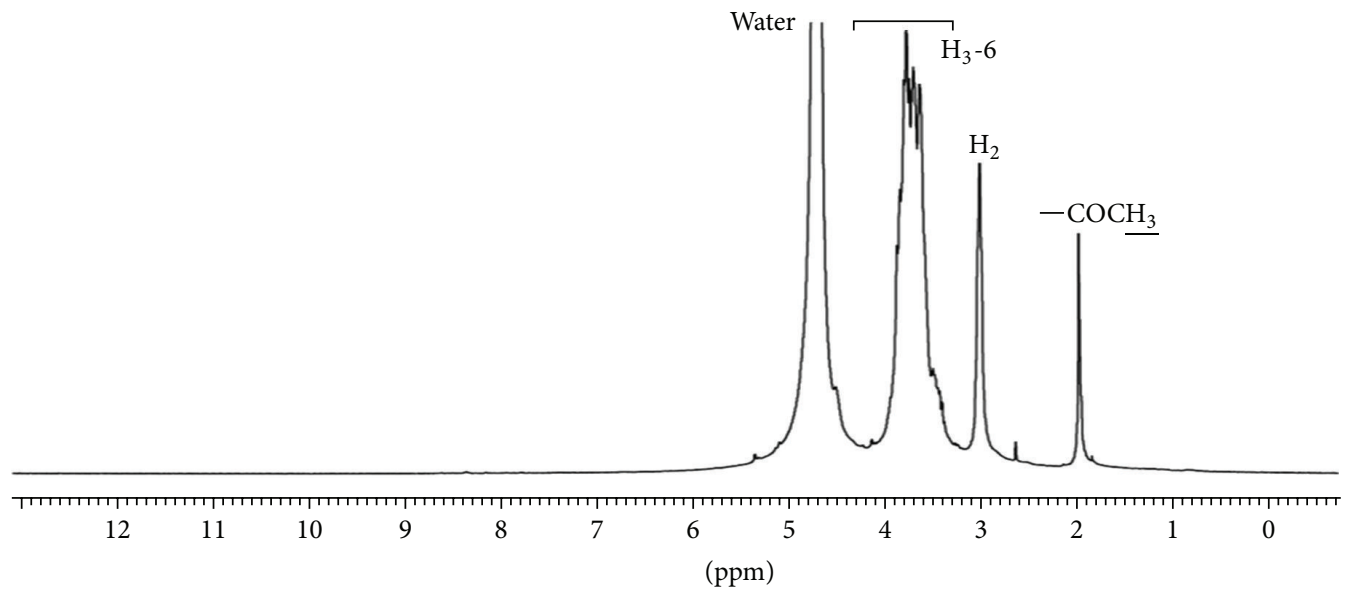

(b)

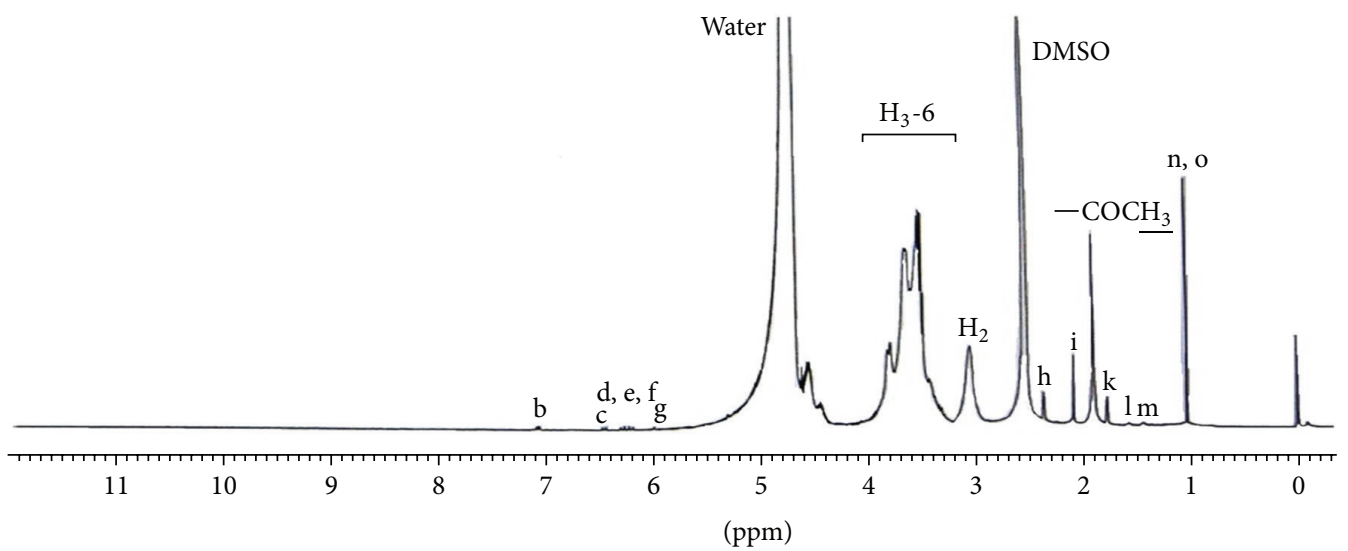

(c)

Figure 1: ${ }^{1}$ H NMR spectra: (a) retinoic acid, (b) chitosan, and (c) retinoic acid-chitosan conjugate.

values of zeta potential. Statistical analysis of our results revealed that in drug content level of 0.25 increasing the albumin to RC ratio had slim effect on zeta potential, but as the albumin concentration was increased, switching to higher level of drug content had quite significant impact on zeta potential.
3.4. Entrapment Efficiency. As it can be seen in Figure 5, the amount of total RC and albumin was the most important factor affecting the entrapment efficiency, while the role of albumin alone was negligible. Therefore, it may be concluded that the main factor was the amount of RC. Increased drug content resulted in lower entrapment efficiency (Table 3). 


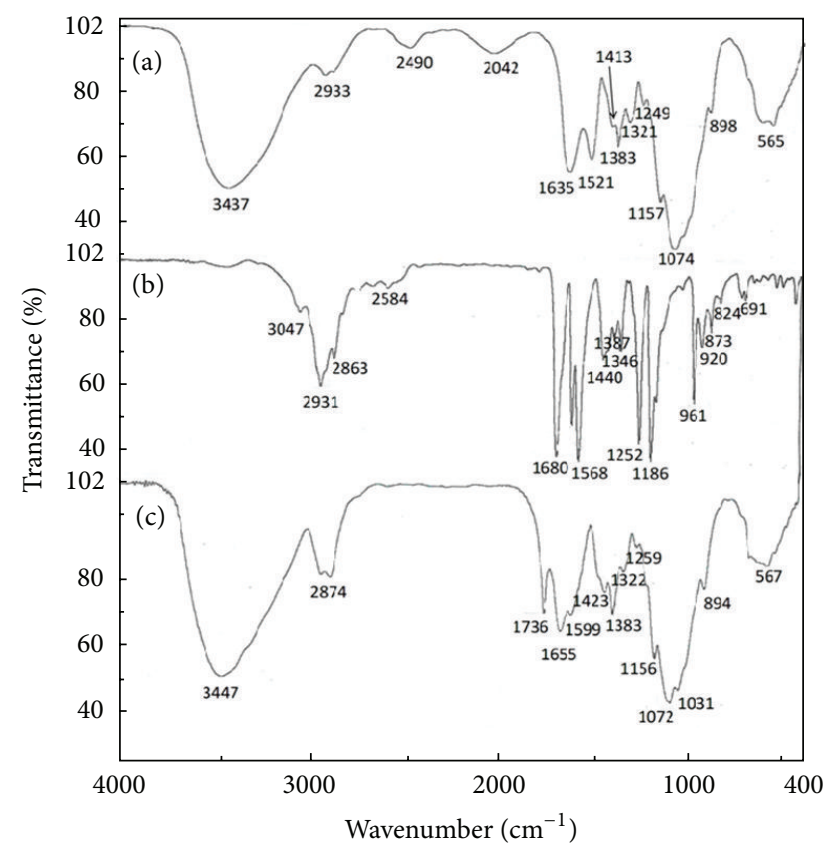

FIGURE 2: FT-IR spectra: (a) chitosan, (b) retinoic acid, (c) retinoic acid-chitosan conjugate.

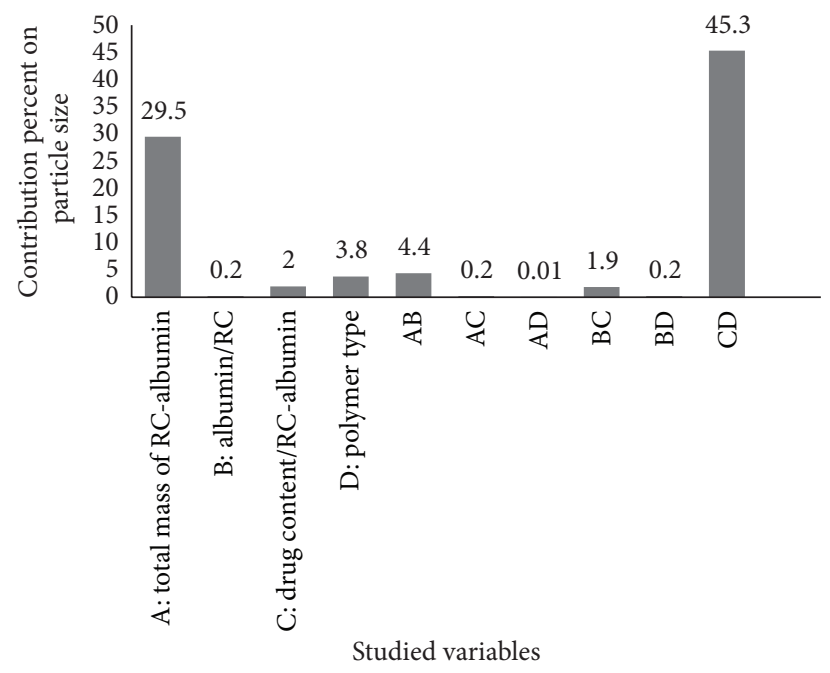

FIGURE 3: Contribution percent of studied variables on the particle size of RC-albumin nanoparticles loaded with doxorubicin.

The interaction of albumin/RC with drug content/albumin$\mathrm{RC}$ was also another effective parameter on doxorubicin entrapment efficiency.

Many factors have been reported to affect the entrapment efficiency of drugs in nanoparticles with chitosan structures such as drug to polymer ratio, chitosan concentration, the properties of the drug itself, and the stirring rate. In present study the stirring rate was set to be the same for all tests so its effect did not interfere in entrapment efficiency.

As mentioned earlier, Figure 5 indicates that the amount of total RC and albumin was the most important factor

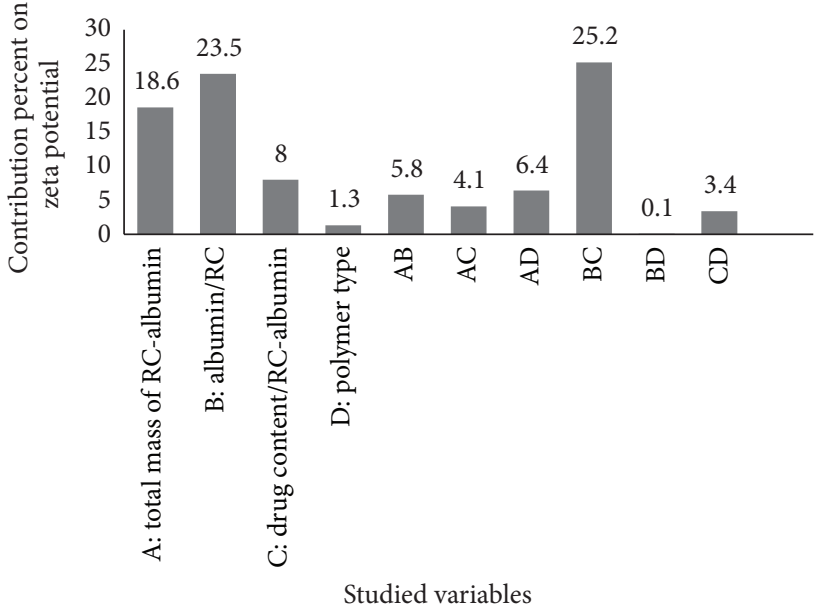

FIGURE 4: Contribution percent of studied variables on the zeta potential of RC-albumin nanoparticles loaded with doxorubicin.

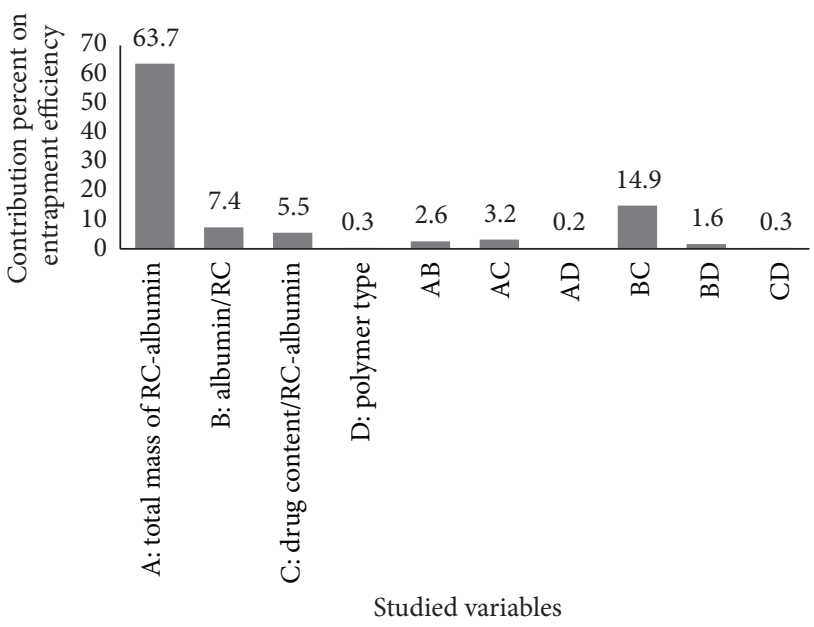

FIGURE 5: Contribution percent of studied variables on entrapment efficiency of RC-albumin nanoparticles loaded with doxorubicin.

affecting the entrapment efficiency, while the role of albumin alone was negligible. Therefore, it may be concluded that the main factor was the amount of RC. Bayomi [37] observed that high concentration of albumin solution and accordingly the increase of albumin-to-chitosan weight ratio were accompanied with increase in particle size and incorporation efficiency of indomethacin in albumin-chitosan microspheres, while a slow drug release was observed.

In another study reported by Bayomi et al. [44], they prepared casein-chitosan microspheres using an aqueous coacervation method to encapsulate diltiazem hydrochloride and reported the amount of protein (casein) as the major variable affecting the entrapment efficiency of the drug.

Although some reports from previous studies $[46,47]$ showed that with higher levels of chitosan concentration used in production of chitosan nanoparticles entrapment efficiency had increased, in the present study statistical analysis of data showed that increase in RC concentration 
TABLE 3: Physicochemical properties of different doxorubicin-loaded RC-albumin nanoparticles.

\begin{tabular}{|c|c|c|c|c|c|}
\hline Formulation code & Particle size (nm) & PdI & Zeta potential (mv) & Loading efficiency\% & $\mathrm{RE}_{60} \%$ \\
\hline $\mathrm{A}_{100} \mathrm{~B}_{1} \mathrm{C}_{0.5} \mathrm{R} 2$ & $357.0 \pm 39.8$ & 0.53 & $39.5 \pm 1.8$ & $33.3 \pm 7.2$ & $41.5 \pm 1.2$ \\
\hline $\mathrm{A}_{10} \mathrm{~B}_{0.5} \mathrm{C}_{0.5} \mathrm{R} 2$ & $232.4 \pm 19.3$ & 0.31 & $43.7 \pm 1.2$ & $40.6 \pm 14.5$ & $66.6 \pm 128$ \\
\hline $\mathrm{A}_{10} \mathrm{~B}_{0.5} \mathrm{C}_{0.25} \mathrm{R} 2$ & $148.0 \pm 16.0$ & 0.44 & $41.3 \pm 3.8$ & $56.8 \pm 13.4$ & $50.5 \pm 9.4$ \\
\hline $\mathrm{A}_{100} \mathrm{~B}_{0.5} \mathrm{C}_{0.5} \mathrm{R} 4$ & $264.5 \pm 86.7$ & 0.77 & $46.8 \pm 3.2$ & $8.3 \pm 2.8$ & $76.8 \pm 2.4$ \\
\hline $\mathrm{A}_{100} \mathrm{~B}_{0.5} \mathrm{C}_{0.5} \mathrm{R} 2$ & $472.2 \pm 78.9$ & 0.94 & $44.8 \pm 1.9$ & $7.3 \pm 6.3$ & $55.6 \pm 3.1$ \\
\hline $\mathrm{A}_{10} \mathrm{~B}_{1} \mathrm{C}_{0.5} \mathrm{R} 2$ & $370.0 \pm 51.9$ & 0.93 & $29.3 \pm 6.9$ & $50.7 \pm 4.7$ & $52.6 \pm 7.8$ \\
\hline $\mathrm{A}_{100} \mathrm{~B}_{1} \mathrm{C}_{0.25} \mathrm{R} 2$ & $234.0 \pm 8.0$ & 0.86 & $45.0 \pm 2.2$ & $28.9 \pm 9.9$ & $54.8 \pm 10.6$ \\
\hline $\mathrm{A}_{100} \mathrm{~B}_{0.5} \mathrm{C}_{0.25} \mathrm{R} 4$ & $340.7 \pm 64.6$ & 0.76 & $41.2 \pm 4.7$ & $32.5 \pm 6.8$ & $32.2 \pm 4.2$ \\
\hline $\mathrm{A}_{10} \mathrm{~B}_{1} \mathrm{C}_{0.5} \mathrm{R} 4$ & $188.0 \pm 65.8$ & 0.94 & $37.4 \pm 6.6$ & $57.7 \pm 7.1$ & $43.4 \pm 3.6$ \\
\hline $\mathrm{A}_{100} \mathrm{~B}_{1} \mathrm{C}_{0.25} \mathrm{R} 4$ & $349.0 \pm 65.3$ & 0.70 & $42.3 \pm 2.3$ & $34.2 \pm 5.1$ & $53.8 \pm 8.1$ \\
\hline $\mathrm{A}_{10} \mathrm{~B}_{0.5} \mathrm{C}_{0.25} \mathrm{R} 4$ & $248.2 \pm 59.3$ & 0.65 & $43.3 \pm 4.2$ & $48.7 \pm 8.0$ & $72 \pm 8.7$ \\
\hline $\mathrm{A}_{10} \mathrm{~B}_{1} \mathrm{C}_{0.25} \mathrm{R} 4$ & $186.4 \pm 18.3$ & 0.74 & $42.5 \pm 0.3$ & $41.1 \pm 26.2$ & $46.4 \pm 5.4$ \\
\hline
\end{tabular}

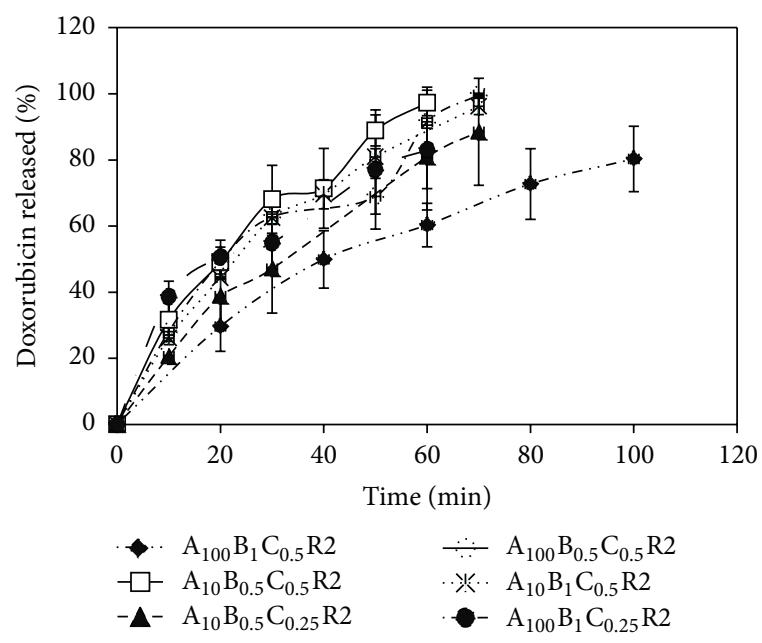

(a)

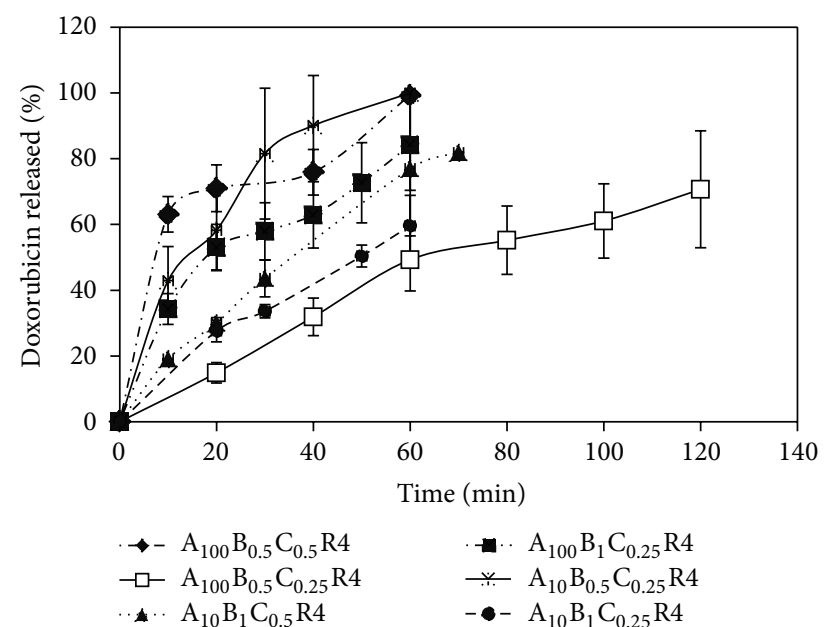

(b)

FiguRE 6: Doxorubicin $\mathrm{HCl}$ release profile from different formulations of RC-albumin nanoparticles prepared from (a) R2 or (b) R4 copolymer with different studied variables (mean $\pm \mathrm{SD}, n=3$ ).

significantly decreased the entrapment efficiency. This might be due to higher viscosity of RC solution in higher concentrations and less chance of the drug to be entrapped into the particles [46]. Moreover, as was mentioned before, doxorubicin has positive charge, so when it came in contact with positively charged RC electrical repulsion inhibited the drug to enter into the nanoparticles, and as the albumin ratio was increased, its negative charge neutralized the total positive charge and entrapment efficiency of doxorubicin was enhanced (Table 3). Increased drug content resulted in lower entrapment efficiency (Table 3), and this effect agreed with what was reported by Sinha et al. [46].

3.5. In Vitro Drug Release Studies. Generally, a fast release profile for doxorubicin was observed in all formulations (Figure 6).

Figure 7 shows the most effective factors that determine release behavior. Some of these variables are the total mass

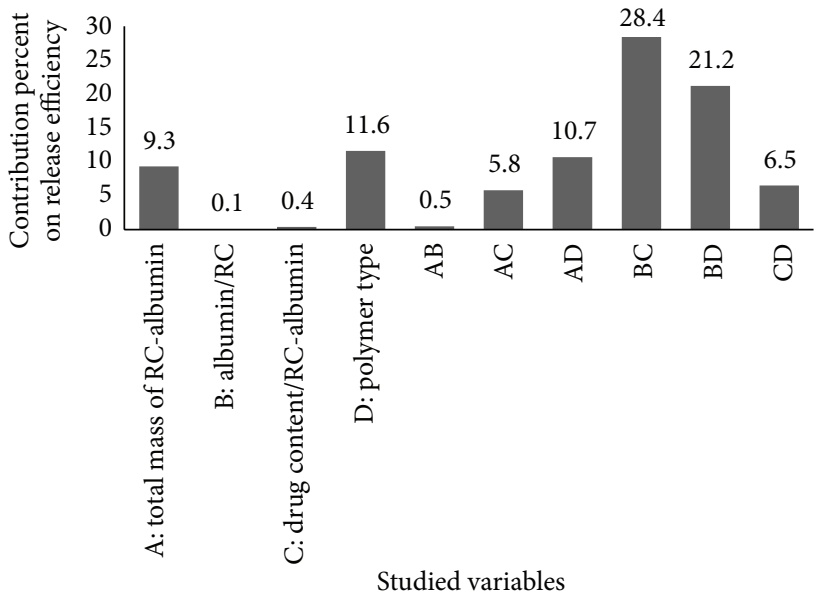

FIgURE 7: Contribution percent of studied variables on release efficiency $\left(\mathrm{RE}_{60} \%\right)$ of RC-albumin nanoparticles loaded with doxorubicin. 
of RC and albumin, polymer type, the interaction of these two variables, the interaction effect of the drug and albumin content, and also the interaction of albumin and polymer type. Statistical analysis of release data showed that increasing the total mass of RC and albumin significantly decreased the RE. Albumin content had low effect on release behavior of doxorubicin from the nanoparticles.

Doxorubicin release profiles from the most of nanoparticle formulations showed a near zero order process (Figure 6). However, some of the nanoparticles especially those prepared with $\mathrm{R} 4$ polymer like $\mathrm{A}_{100} \mathrm{~B}_{0.5} \mathrm{C}_{0.5} \mathrm{R} 4, \mathrm{~A}_{100} \mathrm{~B}_{1} \mathrm{C}_{0.25} \mathrm{R} 4$, and $\mathrm{A}_{10} \mathrm{~B}_{0.5} \mathrm{C}_{0.25} \mathrm{R} 4$ showed a biphasic release pattern for doxorubicin so that at first, a quick release and then a slow phase were observed. The initial rapid release is probably caused by drug release which is dissolved in the surface of nanoparticles that leaks promptly into the release medium, and the next slow release phase is due to the drug diffusion through the core of the nanoparticles matrix.

Statistical analysis of release data showed that increasing the total mass of RC and albumin significantly decreased the RE. Albumin content had low effect on release behavior of doxorubicin from the nanoparticles this effect agrees well with what Nishioka et al. [47] have reported. In the study reported by Bayomi [37] on the release of indomethacin from chitosan-albumin microspheres, they found that higher drug loading around $40 \% \mathrm{w} / \mathrm{w}$ or higher started to interfere with the coacervation process and increased the rate of drug release. Similar results were obtained with coacervation of chitosan with gumkaraya [48], and it was concluded that this effect may be due to an increase in the number of drug particles, which reduced the amount of coacervated phase within the microspheres and might have interfered with cohesion of coacervate. In spite of the reported effect of drug loading (more than 40\%) on the release rate of drug from chitosan-albumin microspheres [37], in our work the drug to polymer ratio was set at 0.5 or 0.25 (Table 2), but still at these high loading its effect on drug release efficiency was negligible (Figure 7). This may be attributed to the different drug solubility of indomethacin (as a low water soluble drug) used in previous studies and doxorubicin $\mathrm{HCl}$ (a quite water soluble drug) used in the present study that does not interfere with coacervation process.

3.6. Optimization. In many formulations, not just pharmaceutical in nature, it is necessary to balance several different measures of quality (i.e., properties) in order to find the best overall product. Changes to the formulation to improve one property may have a deleterious impact on another property. The process of finding the best compromise has been more rigorous by the process of desirability optimization, to produce numerical value of a desirability function.

Computer optimization of the results from irregular factorial design will allow the estimation of a specific combination of the variables that will optimize the individual responses and will yield a product with desirable qualities. The criteria for the optimization of all studied factors are shown in Table 1. Twelve different formulations were designed with Design Expert software by an irregular factorial design. Then considering the results of the experiments done on these formulations (Table 3), optimization was done using Design Expert software, and $\mathrm{A}_{10} \mathrm{~B}_{1} \mathrm{C}_{0.37} \mathrm{R} 2$ was suggested as the optimum formulation which showed a good particle size of $286 \mathrm{~nm}$, zeta potential was $30.5 \mathrm{mV}$, an acceptable entrapment efficiency of $43.6 \%$, and relatively high release efficiency of $56.17 \%$.

Comparing the results predicted by this software for the optimum formulation of nanoparticles with the actual values showed that the error percent was -33\%, $12 \%, 3.11 \%$, and $13 \%$ for particle size, zeta potential, entrapment efficiency, and release efficiency, respectively.

3.7. Transmission Electron Microscopy (TEM) of the Nanoparticles. The morphology of the prepared nanoparticles is shown in Figure 8. The nanoparticles are obviously discrete; some spherical and some irregular shapes and the scale bar of the graphs confirm the particle size of the nanoparticles obtained by PCS method (Table 3).

The results of particle size of the nanoparticles obtained by PCS method (Table 3) were confirmed by the TEM pictures as seen in Figure 8. Although the $\mathrm{pH}$ of the solution was adjusted at 2.49 in all formulations, but some irregularity was seen in the particles. After preliminary studies the, $\mathrm{pH}$ of 2.49 was selected as the cross-linking interaction was initiated at acidic $\mathrm{pH}$ in the presence of amino groups. It was expected as the $\mathrm{pH}$ of solution was increased, the efficiency of crosslinking reaction was decreased and the particles became less rigid, resulting in irregular particles. This trend of changes was maximum at $\mathrm{pH} 4.52$, which is close to the isoelectric point of egg albumin where the molecules are nearly overall electroneutral, and incomplete coacervation (if any) and/or incomplete cross linking of the nanoparticles is possible [38].

3.8. Cell Proliferation Assay. Cell survival percentage of HepG2 cells is shown in Figure 9. Doxorubicin-loaded nanoparticles targeted with retinoic acid (RC-albumin) were compared with nontargeted ones (chitosan-albumin) and free doxorubicin. As can be seen from Figure 9, the $\mathrm{IC}_{50}$ is decreased in both targeted and nontargeted nanoparticles compared to free doxorubicin. The retinoic acid targeted nanoparticles had the lowest $\mathrm{IC}_{50}$. The highest growth inhibitory effect was observed in cells treated with RCalbumin nanoparticles at $0.5 \mu \mathrm{g} / \mathrm{mL}$ concentration that is approximately two and three times greater than the effect observed with nontargeted and free doxorubicin at the same concentration, respectively.

However, the cell survival percentage shows an increase in doxorubicin-loaded RC-albumin nanoparticles-treated group at $1 \mu \mathrm{g} / \mathrm{mL}$ concentration and its blank nanoparticles. Antonyak et al. [49] reported that retinoic acid and its various synthetic analogs affected mammalian cell growth, differentiation, and apoptosis. Whereas treatment of the human leukemia cell line HL60 with retinoic acid resulted in cellular differentiation, addition of the synthetic retinoid, $\mathrm{N}$-(4-hydroxyphenyl) retinamide (HPR), and induced HL60 cells to undergo apoptosis. Moreover, pretreatment of HL60 cells as well as other cell lines (i.e., NIH3T3 cells) with retinoic acid blocked HPR-induced cell death. Therefore, 


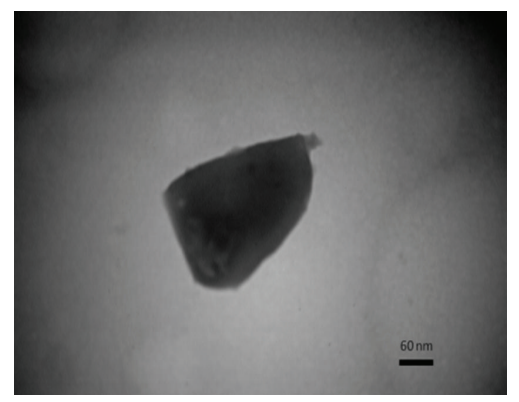

(a)

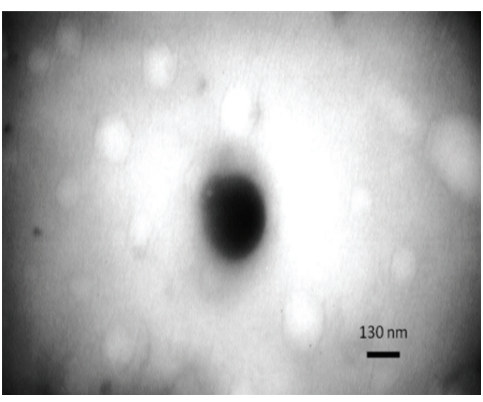

(b)

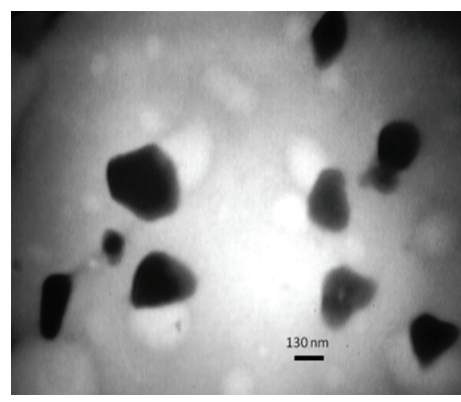

(c)

FIGURE 8: TEM micrographs of RC-albumin nanoparticles loaded with doxorubicin with different magnifications.

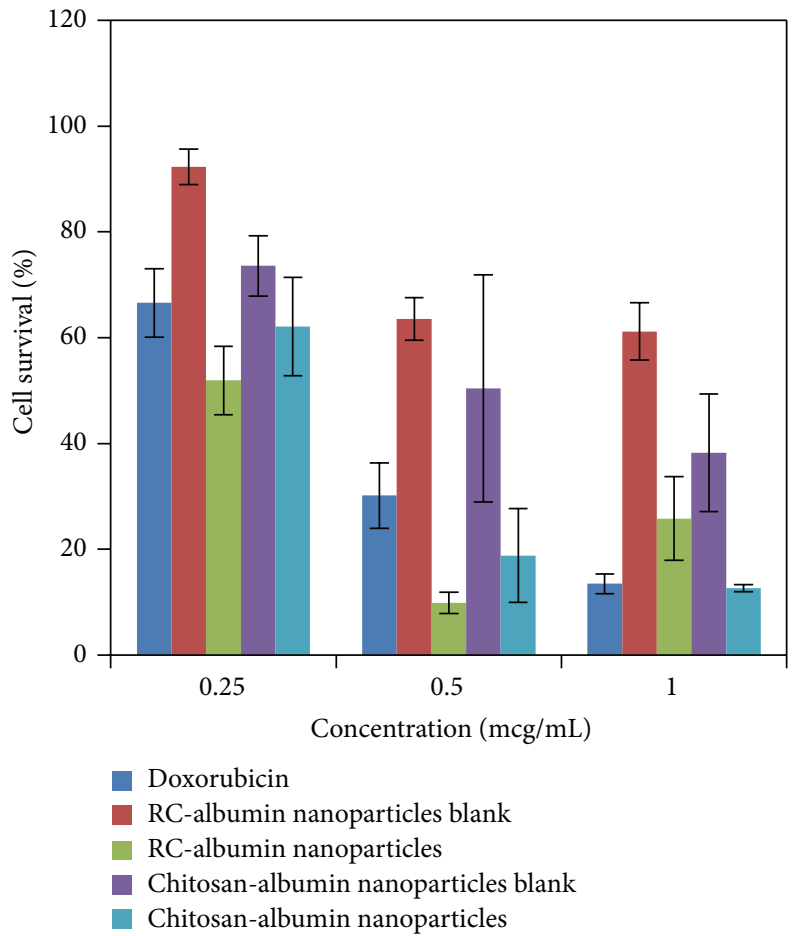

FIGURE 9: Viability of HepG2 cells after treatment with different concentrations of doxorubicin-loaded nanoparticles of chitosanalbumin with or without retinoic acid conjugate in comparison with free doxorubicin by MTT assay $(n=3)$.

it may be concluded that the growth inhibitory effect of retinoic acid on HepG2 cells that is exerted via $\alpha$-receptors over expressed in hepatocellular carcinoma may be dose dependent. When the concentration of nanoparticles was increased to deliver $1 \mu \mathrm{g} / \mathrm{mL}$ of doxorubicin to the cells, the concentration of carrier itself, that is, RC-albumin, was increased too, and the increased retinoic acid may have blocked cell death induced by doxorubicin that is loaded in $\mathrm{RC}$-albumin nanoparticles. Consequently the viable cells had increased at $1 \mu \mathrm{g} / \mathrm{mL}$ concentration.

3.9. Cellular Uptake Study. The results are represented in Figure 10. As this figure shows after $1 \mathrm{hr}$ of incubation just
RC-albumin nanoparticles show a brief accumulation of fluorescence in the cells. After $4 \mathrm{hr}$, the green fluorescence is sighted more significantly in cells that are incubated with sodium fluorescein loaded in RC-albumin nanoparticles than nontargeted chitosan-albumin nanoparticles, and there is no significant fluorescence in cells that are incubated with solution of sodium fluorescein. It should be reminded that after loading the nanoparticles with the fluorescein solution, the free fluorescein was removed from the solution by dialysis method, and just the washed loaded nanoparticles were exposed to the cells.

These results depict robust uptake of the nanoparticles in HepG 2 cells. Control cells incubated with free solution of fluorescein did not show any fluorescence. The cells incubated with nontargeted nanoparticles (chitosan-albumin) loaded with fluorescein exhibited a brief green fluorescence compared to rapid internalization and accumulation of retinoic acid targeted nanoparticles (RC-albumin) by the cancer cells (Figure 10). Further investigation on the mechanism of retinoic acid targeted nanoparticles uptake, and the kinetics of drug uptake and retention in the HepG2 cells compared to a free drug in vivo will be useful to establish the efficacy of nanoparticles for various therapeutic applications.

\section{Conclusions}

Chitosan-albumin nanoparticles targeted with $\mathrm{R}$ were prepared for targeted delivery of doxorubicin to hepatocellular carcinoma. R was grafted to chitosan by DCC-NHS chemistry, and RC copolymer was synthesized successfully. An aqueous coacervation method was used to attach albumin to RC copolymer. Preparation of the targeted nanoparticles of RC-albumin containing doxorubicin was optimized statistically by an irregular factorial design. The best formulation of the RC-albumin nanoparticles was $\mathrm{A}_{10} \mathrm{~B}_{1} \mathrm{C}_{0.37} \mathrm{R} 2$ which was prepared by copolymer of chitosan and retinoic acid in which 2 amine groups were substituted, $10 \mathrm{mg}$ of RCalbumin was used in its preparation, the ratio of albu$\mathrm{min} / \mathrm{RC}$ was 1 and the ratio of drug/RC-albumin was 0.37 . The particle size of these nanoparticles was $286 \mathrm{~nm}$, zeta potential of $30.5 \mathrm{mV}$, an acceptable entrapment efficiency of $43.6 \%$, and relatively high release efficiency of $56.17 \%$ until $1 \mathrm{hr}$ of release test. The highest growth inhibitory effect was observed in HepG2 cells treated with RC-albumin 

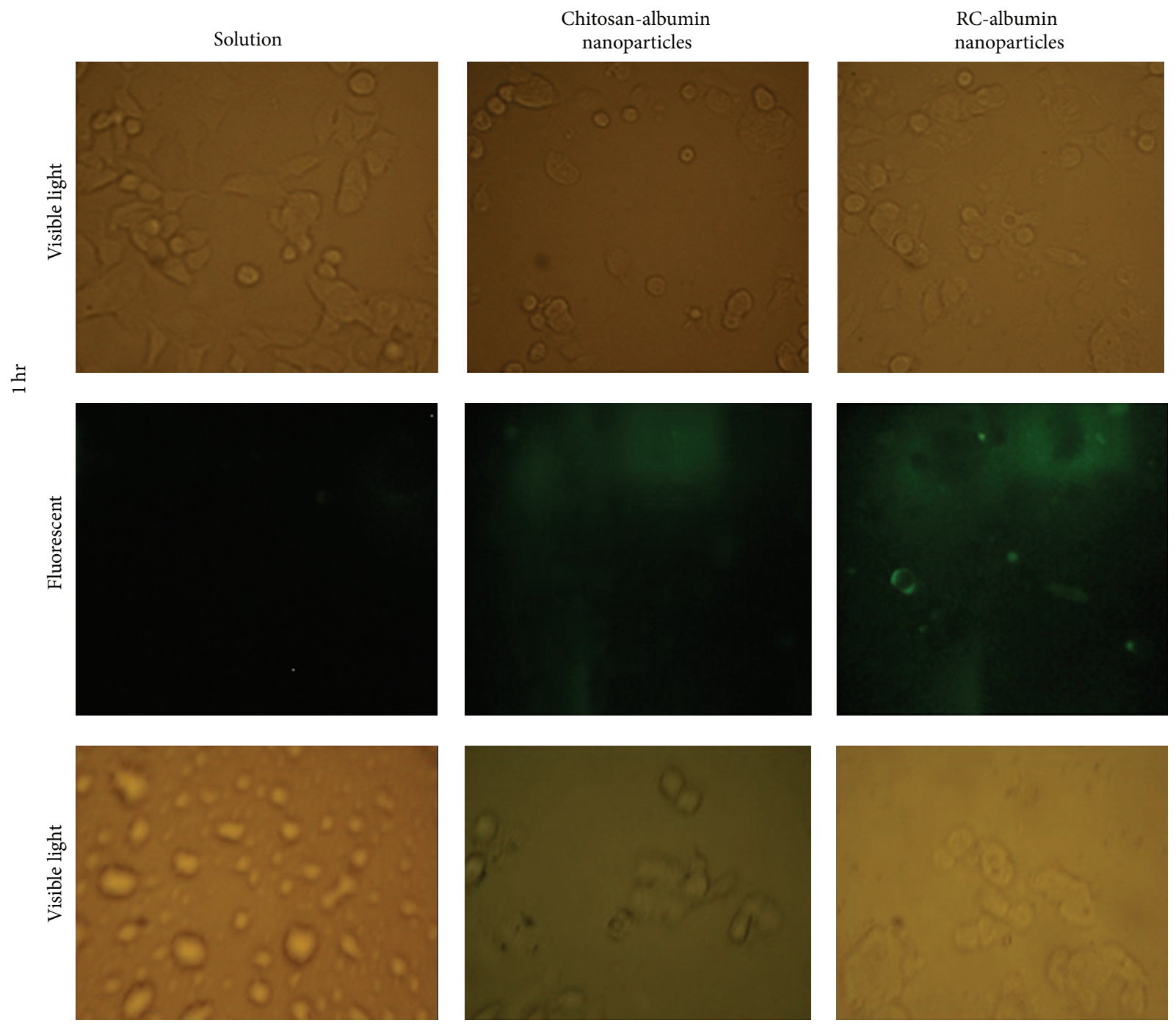

$\stackrel{\xi}{\not}$
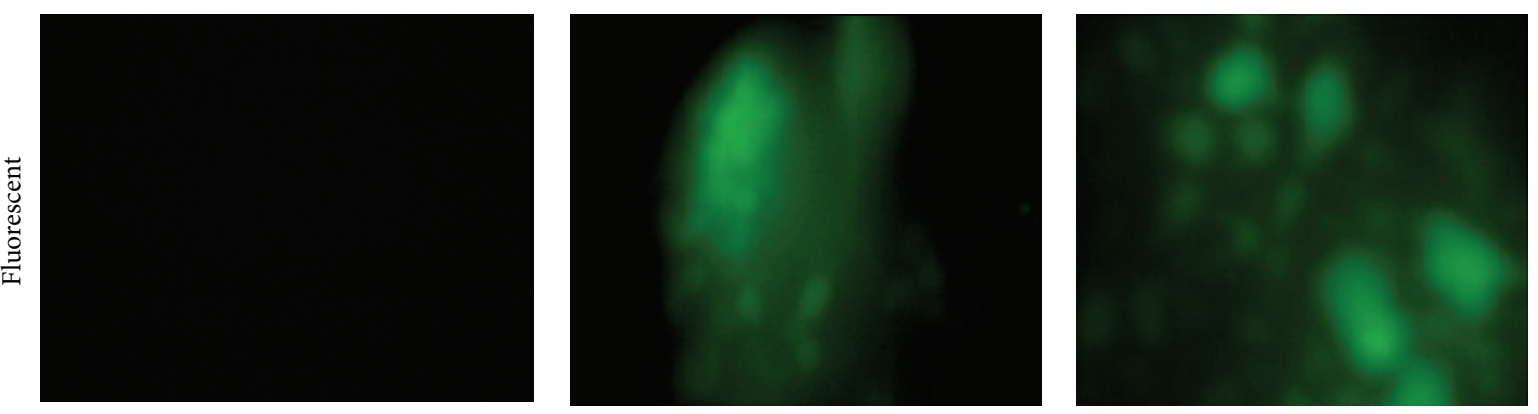

FIGURE 10: Fluorescent and visible light microscopic images of HepG2 cells after incubation with fluorescein loaded in nanoparticles of RCalbumin and chitosan-albumin or as free fluorescein solution for 1 and $4 \mathrm{hr}$.

nanoparticles at $0.5 \mu \mathrm{g} / \mathrm{mL}$ concentration that is approximately two and three times greater than the effect observed by nontargeted and free doxorubicin at the same concentration, respectively. This may reduce needed dose of doxorubicin and consequently reduces the required doses which in turn reduces the cardiotoxicity of this drug. The results should be checked in vivo to confirm the promising results on the cell culture.

\section{Conflict of Interests}

There is not any conflict of interests.

\section{Acknowledgments}

The authors acknowledge the financial support of Isfahan University of Medical Sciences. This paper is extracted from the dissertation of Zahra Ghelich Khan the PharmD student 
of Faculty of Pharmacy of Isfahan University of Medical Sciences.

\section{References}

[1] H. B. El-Serag, "Hepatocellular carcinoma: an epidemiologic view," Journal of Clinical Gastroenterology, vol. 35, supplement 5, pp. S27-S28, 2002.

[2] J. M. Llovet, S. Ricci, V. Mazzaferro et al., "Sorafenib in advanced hepatocellular carcinoma," The New England Journal of Medicine, vol. 359, no. 4, pp. 378-390, 2008.

[3] D. M. Parkin, F. Bray, J. Ferlay, and P. Pisani, "Global cancer statistics, 2002," Ca: A Cancer Journal for Clinicians, vol. 55, no. 2, pp. 74-108, 2005.

[4] H. B. El-Serag and K. L. Rudolph, "Hepatocellular carcinoma: epidemiology and molecular carcinogenesis," Gastroenterology, vol. 132, no. 7, pp. 2557-2576, 2007.

[5] V. K. Rustgi, "Epidemiology of hepatocellular carcinoma," Gastroenterology Clinics of North America, vol. 16, no. 4, pp. 545-551, 1987.

[6] W. T. London, "Primary hepatocellular carcinoma-etiology, pathogenesis, and prevention," Human Pathology, vol. 12, no. 12, pp. 1085-1097, 1981.

[7] C. L. Lai, P. B. Gregory, P. C. Wu, A. S. F. Lok, K. P. Wong, and M. M. T. Ng, "Hepatocellular carcinoma in Chinese males and females. Possible causes for the male predominance," Cancer, vol. 66, no. 5, pp. 1107-1110, 1987.

[8] C. Muir, J. Waterhouse, J. Powell, T. Mack, and S. Whelan, Cancer Incidence in Five Continents, Volume 5, Oxford University Press, New York, NY, USA, 1987.

[9] S. R. Nerenstone, D. C. Ihde, and M. A. Friedman, "Clinical trials in primary hepatocellular carcinoma: current status and future directions," Cancer Treatment Reviews, vol. 15, no. 1, pp. 1-31, 1988.

[10] M. A. Avila, C. Berasain, B. Sangro, and J. Prieto, "New therapies for hepatocellular carcinoma," Oncogene, vol. 25, no. 27, pp. 3866-3884, 2006.

[11] M. Huang and G. Liu, "The study of innate drug resistance of human hepatocellular carcinoma $B_{7402}$ cell line," Cancer Letters, vol. 135, no. 1, pp. 97-107, 1999.

[12] J. M. Llovet, A. Burroughs, and J. Bruix, "Hepatocellular carcinoma," The Lancet, vol. 362, no. 9399, pp. 1907-1917, 2003.

[13] P. B. Jensen, B. S. Sorensen, M. Sehested et al., "Different modes of anthracycline interaction with topoisomerase II. Separate structures critical for DNA-cleavage, and for overcoming topoisomerase II-related drug resistance," Biochemical Pharmacology, vol. 45, no. 10, pp. 2025-2035, 1993.

[14] K. Shan, A. Michael Lincoff, and J. B. Young, "Anthracyclineinduced cardiotoxicity," Annals of Internal Medicine, vol. 125, no. 1, pp. 47-58, 1996.

[15] E. Ruoslahti, S. N. Bhatia, and M. J. Sailor, "Targeting of drugs and nanoparticles to tumors," Journal of Cell Biology, vol. 188, no. 6, pp. 759-768, 2010.

[16] T. J. Harris, G. von Maltzahn, M. E. Lord et al., "Proteasetriggered unveiling of bioactive nanoparticles," Small, vol. 4, pp. 1307-1312, 2008.

[17] S. M. Moghimi, A. C. Hunter, and J. C. Murray, "Long-circulating and target-specific nanoparticles: theory to practice," Pharmacological Reviews, vol. 53, no. 2, pp. 283-318, 2001.

[18] S. Wagner, F. Rothweiler, M. G. Anhorn et al., "Enhanced drug targeting by attachment of an anti $\alpha \mathrm{v}$ integrin antibody to doxorubicin loaded human serum albumin nanoparticles," Biomaterials, vol. 31, no. 8, pp. 2388-2398, 2010.

[19] J. Chen, H. Wu, D. Han, and C. Xie, "Using anti-VEGF McAb and magnetic nanoparticles as double-targeting vector for the radioimmunotherapy of liver cancer," Cancer Letters, vol. 231, no. 2, pp. 169-175, 2006.

[20] P. Liu, Z. Li, M. Zhu et al., "Preparation of EGFR monoclonal antibody conjugated nanoparticles and targeting to hepatocellular carcinoma," Journal of Materials Science, vol. 21, no. 2, pp. 551-556, 2010.

[21] T. H. Kim, I. K. Park, J. W. Nah, Y. J. Choi, and C. S. Cho, "Galactosylated chitosan/DNA nanoparticles prepared using water-soluble chitosan as a gene carrier," Biomaterials, vol. 25, no. 17, pp. 3783-3792, 2004.

[22] K. Sano, T. Takayama, K. Murakami, I. Saiki, and M. Makuuchi, "Overexpression of retinoic acid receptor $\alpha$ in hepatocellular carcinoma," Clinical Cancer Research, vol. 9, no. 10 I, pp. 36793683, 2003.

[23] J. Edeline, J. L. Raoul, E. Vauleon, A. Guillygomac'h, K. Boudjema, and E. Boucher, "Systemic chemotherapy for hepatocellular carcinoma in non-cirrhotic liver: a retrospective study," World Journal of Gastroenterology, vol. 15, no. 6, pp. 713-716, 2009.

[24] C. E. Sever and J. Locker, "Expression of retinoic acid $\alpha$ and $\beta$ receptor genes in liver and hepatocellular carcinoma," Molecular Carcinogenesis, vol. 4, no. 2, pp. 138-144, 1991.

[25] T. T. Schug, D. C. Berry, N. S. Shaw, S. N. Travis, and N. Noy, "Opposing effects of retinoic acid on cell growth result from alternate activation of two different nuclear receptors," Cell, vol. 129, no. 4, pp. 723-733, 2007.

[26] F. Recchia, G. Saggio, A. Cesta et al., "Phase II study of interleukin-2 and 13-cis-retinoic acid as maintenance therapy in metastatic colorectal cancer," Cancer Immunology, Immunotherapy, vol. 56, no. 5, pp. 699-708, 2007.

[27] J. Guo, B. Xiao, Y. Lou et al., "Antitumor effects of alltrans-retinoic acid on cultured human pancreatic cancer cells," Journal of Gastroenterology and Hepatology, vol. 21, no. 2, pp. 443-448, 2006.

[28] A. M. Tsimberidou, M. Tirado-Gomez, M. Andreeff et al., "Single-agent liposomal all-trans retinoic acid can cure some patients with untreated acute promyelocytic leukemia: an update of The University of Texas M. D. Anderson Cancer Center Series," Leukemia and Lymphoma, vol. 47, no. 6, pp. 1062-1068, 2006.

[29] B. Singh, R. F. Murphy, X. Z. Ding, A. B. Roginsky, R. H. Bell Jr., and T. E. Adrian, "On the role of transforming growth factor$\beta$ in the growth inhibitory effects of retinoic acid in human pancreatic cancer cells," Molecular Cancer, vol. 6, article no. 82, 2007.

[30] L. Altucci and H. Gronemeyer, "The promise of retinoids to fight against cancer," Nature Reviews Cancer, vol. 1, no. 3, pp. 181-193, 2001.

[31] M. P. Patel, R. R. Patel, and J. K. Patel, "Chitosan mediated targeted drug delivery system: a review," Journal of Pharmacy and Pharmaceutical Sciences, vol. 13, no. 4, pp. 536-557, 2010.

[32] S. Hirano, H. Seino, Y. Akiyama, and I. Nonaka, "Chitosan: a biocompatible material for oral and intravenous administration," in Progress in Biomedical Polymers, C. G. Gebelein and R. L. Dunn, Eds., Plenum Press, New York, NY, USA, 1990.

[33] Y. Zheng, Z. Cai, X. Song et al., "Preparation and characterization of folate conjugated $\mathrm{N}$-trimethyl chitosan nanoparticles 
as protein carrier targeting folate receptor: in vitro studies," Journal of Drug Targeting, vol. 17, no. 4, pp. 294-303, 2009.

[34] K. Y. Lee, I. C. Kwon, Y. H. Kim, W. H. Jo, and S. Y. Jeong, "Preparation of chitosan self-aggregates as a gene delivery system," Journal of Controlled Release, vol. 51, no. 2-3, pp. 213-220, 1998.

[35] L. Chen and M. Subirade, "Chitosan/ $\beta$-lactoglobulin core-shell nanoparticles as nutraceutical carriers," Biomaterials, vol. 26, no. 30, pp. 6041-6053, 2005.

[36] T. W. Wang, Q. Xu, Y. Wu, A. J. Zeng, M. Li, and H. Gao, "Quaternized chitosan (QCS)/poly (aspartic acid) nanoparticles as a protein drug-delivery system," Carbohydrate Research, vol. 344, no. 7, pp. 908-914, 2009.

[37] M. A. Bayomi, "Aqueous preparation and evaluation of albumin-chitosan microspheres containing indomethacin," Drug Development and Industrial Pharmacy, vol. 30, no. 4, pp. 329-339, 2004.

[38] A. O. Elzoghby, W. M. Samy, and N. A. Elgindy, "Albumin-based nanoparticles as potential controlled release drug delivery systems," Journal of Controlled Release, vol. 157, no. 2, pp. 168182, 2012.

[39] E. C. van Dalen, E. M. Michiels, H. N. Caron, and L. C. Kremer, "Different anthracycline derivates for reducing cardiotoxicity in cancer patients," Cochrane Database of Systematic Reviews, vol. 3, Article ID CD005006, 2010.

[40] A. Fattahi, M. A. Golozar, J. Varshosaz, M. H. Sadeghi, and M. Fathi, "Preparation and characterization of micelles of oligomeric chitosan linked to all trans retinoic acid," Carbohydrate Polymers, vol. 87, pp. 1176-1184, 2012.

[41] J. Qi, P. Yao, F. He, C. Yu, and C. Huang, "Nanoparticles with dextran/chitosan shell and BSA/chitosan core-doxorubicin loading and delivery," International Journal of Pharmaceutics, vol. 393, no. 1-2, pp. 176-184, 2010.

[42] E. B. Denkbaş, E. Kiliçay, C. Birlikseven, and E. Öztürk, "Magnetic chitosan microspheres: preparation and characterization," Reactive and Functional Polymers, vol. 50, pp. 225-232, 2002.

[43] Y. B. Ge, D. W. Chen, L. P. Xie, and R. Q. Zhang, "Optimized preparation of daidzein-loaded chitosan microspheres and in vivo evaluation after intramuscular injection in rats," International Journal of Pharmaceutics, vol. 338, no. 1-2, pp. 142-151, 2007.

[44] M. A. Bayomi, S. A. Al-Suwayeh, A. M. El-Helw, and A. F. Mesnad, "Preparation of casein-chitosan microspheres containing diltiazem hydrochloride by an aqueous coacervation technique," Pharmaceutica Acta Helvetiae, vol. 73, no. 4, pp. 187192, 1998.

[45] C. Freitas and R. H. Müller, "Effect of light and temperature on zeta potential and physical stability in solid lipid nanoparticle (SLN) dispersions," International Journal of Pharmaceutics, vol. 168, no. 2, pp. 221-229, 1998.

[46] V. R. Sinha, A. K. Singla, S. Wadhawan et al., "Chitosan microspheres as a potential carrier for drugs," International Journal of Pharmaceutics, vol. 274, no. 1-2, pp. 1-33, 2004.

[47] Y. Nishioka, S. kyotani, H. Masui et al., "Preparation and release characteristics of cisplatin albumin microspheres containing chitin and treated with chitosan," Chemical and Pharmaceutical Bulletin, vol. 37, no. 11, pp. 3074-3077, 1989.

[48] G. V. M. M. Babu, C. D. S. Prasad, C. P. S. Narayan, and K. V. R. Murthy, "New system for microencapsulation of diclofenac sodium using gum karaya and chitosan," Saudi Pharmaceutical Journal, vol. 9, no. 3-4, pp. 169-178, 2001.
[49] M. A. Antonyak, U. S. Singh, D. A. Lee et al., "Effects of tissue trans glutaminase on retinoic acid-induced cellular differentiation and protection against a poptosis," The Journal of Biological Chemistry, vol. 276, no. 36, pp. 33582-33587, 2001. 

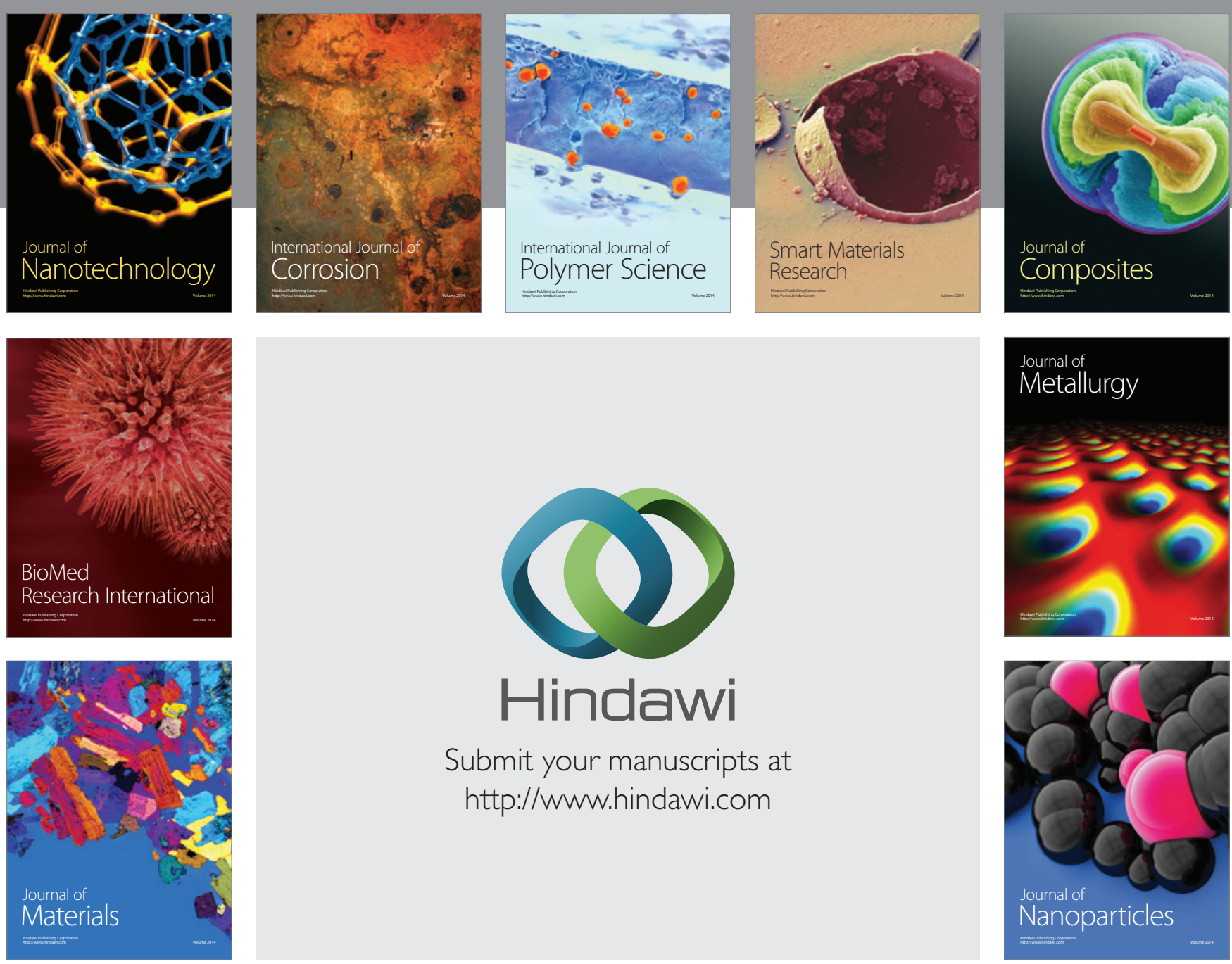

Submit your manuscripts at http://www.hindawi.com
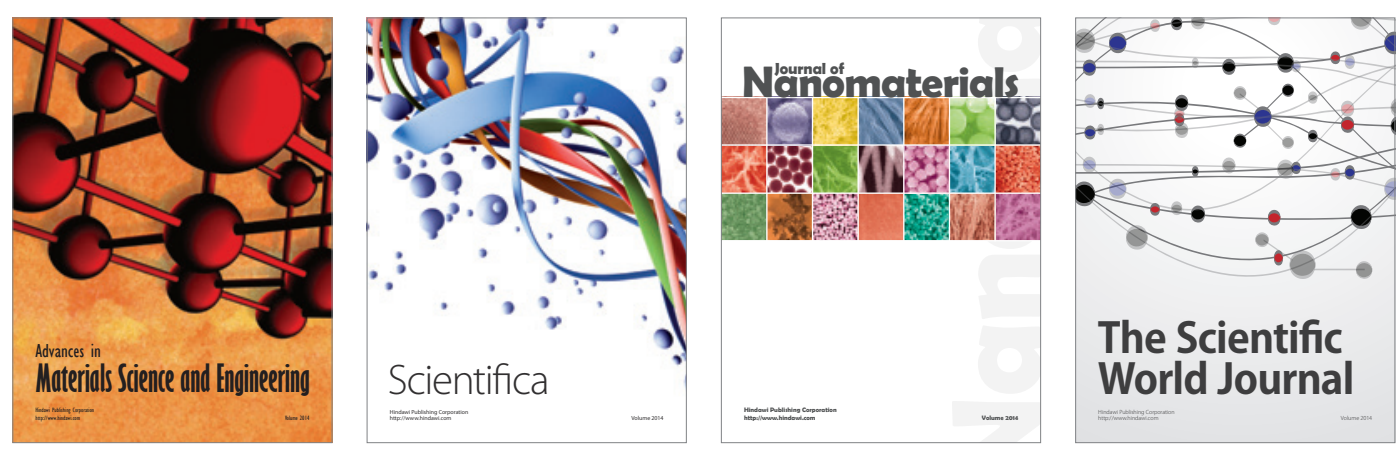

\section{The Scientific World Journal}
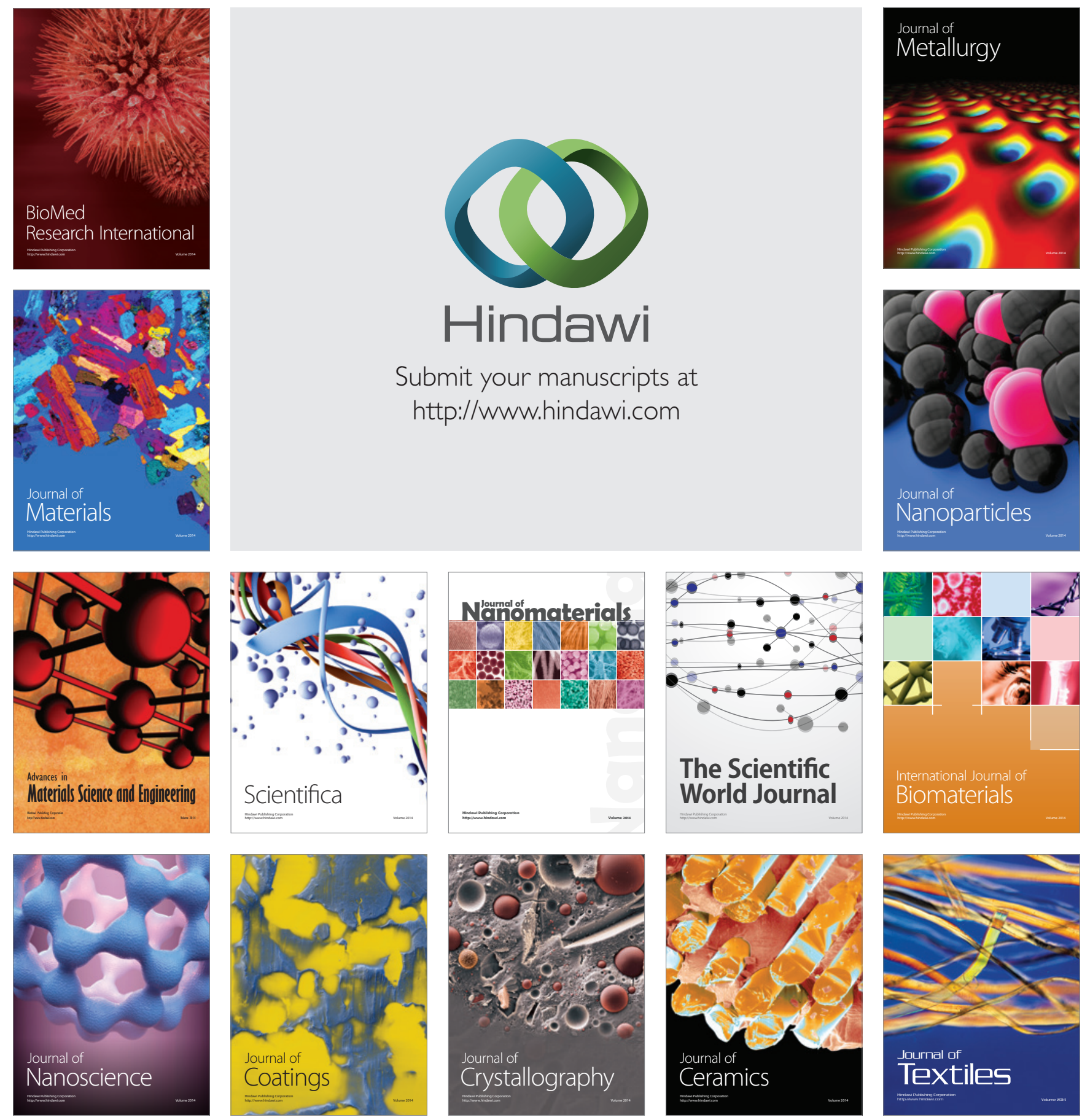